\title{
LAJU PERTUMBUHAN RUMPUT LAUT Gracillaria sp. PADA KEDALAMAN DAN JARAK TANAM BERBEDA DI KECAMATAN BLANAKAN KABUPATEN SUBANG
}

\author{
Oleh : \\ Sopyan Danapraja, lis Jubaedah dan Pigoselpi Anas \\ Dosen Jurusan Penyuluhan Perikanan Sekolah Tinggi Perikanan
}

\begin{abstract}
ABSTRAK
Penelitian ini bertujuan untuk mengetahui laju pertumbuhan Gracilaria sp. pada kedalaman dan jarak tanam yang berbeda. Perlakuan yang diberikan adalah kedalaman (permukaan, 30 dan $60 \mathrm{~cm}$ dari permukaan) dan jarak tanam $(20,25$ dan $30 \mathrm{~cm})$ dengan tiga kali ulangan menggunakan metode budidaya lepas dasar.

Hipotesa yang diajukan "Diduga, kedalaman dan jarak tanam memberikan pengaruh berbeda terhadap laju pertumbuhan rumput laut Gracilaria sp. yang dibudidayakan di tambak dengan metode lepas dasar. Laju pertumbuhan tanaman uji dianalisa menggunakan persamaan pertumbuhan eksposional (Ricker, 1975). Model Klasifikasi Dua Arah dengan Anak Contoh (Boer, 1989) digunakan untuk menguji hipotesis.

Hasil penelitian menunjukkan bahwa laju pertumbuhan Gracilaria sp. yang ditanam di permukaan dengan jarak tanam yang sama mempunyai rata-rata laju pertumbuhan lebih tinggi dari yang ditanam di kedalaman 30 dan $60 \mathrm{~cm}$, dan rata-rata laju pertumbuhan yang dibedakan atas jarak tanam $(20,25$ dan $30 \mathrm{~cm})$ pada kedalaman dipermukaan menunjukkan jarak tanam $30 \mathrm{~cm}$ mempunyai laju pertumbuhan tertinggi. Berdasarkan hasil Analisis Sidik Ragam maupun uji Duncan memperlihatkan bahwa perbedaan kedalaman berpengaruh nyata, sedangkan perbedaan jarak tanam tidak berpengaruh nyata terhadap laju pertumbuhan.
\end{abstract}

Kata kunci : Laju pertumbuhan, Gracilaria sp., Kedalaman, Jarak tanam

\section{PENDAHULUAN}

\section{Latar Belakang}

Pemanfaatan rumput laut di bidang industri makanan, kosmetik dan obat-obatan semakin meluas di berbagai negara, sehingga permintaan akan bahan baku rumput laut cenderung terus meningkat. Produksi rumput laut Indonesia belum dapat memenuhi permintaan pasar dalam dan luar negeri. Salah satu daya tarik dari usaha budidaya rumput laut adalah daya resap pasar yang tinggi. Nilai perdagangan komoditas rumput laut dunia saat ini diperkirakan mengalami pertumbuhan sebesar $10 \%$ setiap tahunnya. Pada Tahun 2008-2009 volume kebutuhan dunia rumput laut jenis Eucheuma sp sekitar 235.300 ton dan untuk Gracillia sp sekitar 95.840 ton. Produksi luar negeri untuk Eucheuma sp baru mencapai 145.000 ton dan untuk Gracillaria sp baru mencapai 48.500 ton. Sedangkan Indonesia saat ini baru bisa memproduksi sebesar 90.300 ton Eucheuma sp dan 47.340 ton Gracilia sp (KKP, 2010). 
Gracillaria sp adalah jenis rumput laut penghasil agar-agar yang banyak diusahakan dan mempunyai nilai komersial yang tinggi di Indonesia. Secara taksonomi, rumput laut digolongkan kedalam devisi Thalophyta. Rumput laut hidup dengan menancapkan atau melekatkan dirinya pada substrat lumpur, pasir, karang, fragmen karang mati, batu ataupun kayu. Pertumbuhan dan penyebaran rumput laut sangat tergantung dari faktor-faktor oseanografi (fisika, kimia, dan pergerakan atau dinamika air) serta jenis substrat dasarnya. Untuk pertumbuhannya, rumput laut mengambil nutrisi dari sekitarnya secara difusi melalui dinding thallusnya. Perkembangbiakannya dilakukan dengan dua cara, yaitu secara kawin antara gamet jantan dan gamet betina (generatif) serta secara tidak kawin melalui vegetatif dan konjugatif.

Di perairan laut Indonesia terdapat 196 algae hijau, 134 algae coklat, dan 542 algae merah. Dari berbagi jenis rumput laut tersebut terdapat beberapa jenis bernilai ekonomis penting, jenis-jenis tersebut yaitu Euheuma sp (Eucheuma cottonii dan Eucheuma spinosum), Gracillaria (Gracillaria gigas dan Gracillaria verrucosa), Gelidium sp., Hypnea sp., dan Sargassum sp.

Gracillaria sp merupakan salah satu jenis rumput laut yang banyak dibudidayakan petambak. Gracillaria sp merupakan jenis rumput laut yang dapat dibudidayakan di muara sungai atau di tambak, meskipun habitat awalnya berasal dari laut. Hal ini terjadi karena tingkat toleransi hidup yang tinggi terhadap salinitas sampai pada salinitas $15-30$ ppt.

\section{Tujuan Penelitian}

Penelitian ini bertujuan untuk mengetahui laju pertumbuhan Gracilaria sp. pada kedalaman dan jarak tanam yang berbeda, sehingga diharapkan dapat diketahui kedalaman dan jarak tanam yang dapat menghasilkan laju pertumbuhan yang paling baik.

\section{Manfaat}

Manfaat yang diharapkan dari penelitian ini adalah informasi tentang, umur panen, kedalaman dan jarak tanam berapa pertumbuhan rumput Gracillaria sp yang baik, sehingga dapat meningkatkan produksi rumput laut dan kandungan agar atau karaginan yang dikandungnya serta gelstrength tetap dipertahankan.

\section{METODE PENELITIAN}

\section{Metode Pengumpulan Data}

Penelitian terdiri dari perlakuan kedalaman dan jarak tanam, dengan 3 (tiga) kali ulangan. Metode budidaya yang digunakan adalah lepas dasar dengan kedalaman penanaman yang berbeda yaitu di permukaan perairan, kedalaman $30 \mathrm{~cm}$ dan kedalaman $60 \mathrm{~cm}$ dari permukaan perairan, dan perbedaan jarak tanam yaitu 20,25 , dan $30 \mathrm{~cm}$.

Penimbangan dilakukan setiap tujuh hari sekali (satu minggu) selama satu setengah bulan (6 minggu). Banyaknya contoh yang ditimbang adalah 3 rumpon untuk setiap perlakuan, setelah penimbangan rumpon diikatkan kembali ke posisi semula.

\section{Hipotesa}

Hipotesa yang diajukan dalam penelitian ini adalah : "Diduga, kedalaman dan jarak tanam memberikan pengaruh berbeda terhadap laju pertumbuhan rumput laut Gracillaria sp. yang dibudidayakan di tambak dengan metode lepas dasar". Hipotesa ini diajukan dengan asumsi bahwa intensitas cahaya dan kerapatan tanaman berpengaruh terhadap laju pertumbuhan 
rumput laut sedangkan keadaan lingkungan dianggap sama.

\section{Metode Analisa Data}

Untuk mengetahui laju pertumbuhan tanaman uji digunakan persamaan pertumbuhan Eksposional (Ricker, 1975) yaitu :

$$
\frac{W_{t}}{W_{0}}=e^{b t} \text { atau } W_{t}=W_{0} \cdot e^{b t}
$$

Keterangan :

$W_{t}=$ bobot pada saat $\mathrm{t}$

$W_{0}=$ bobot pada saat $\mathrm{t}$ sama dengan o

$\mathrm{b}=$ laju pertumbuhan seketika

$\mathrm{t}=$ waktu (minggu)

Bobot rumput laut pada suatu satuan waktu sama dengan W1, sehingga persamaan pertumbuhan (1) dapat ditulis menjadi $\frac{W_{1}}{W_{0}}=e^{b}$. Adapun laju pertumbuhan relatif (h) dibatasi sebagai: $\frac{W_{1}-W_{0}}{W_{0}}=\frac{W_{1}}{W_{0}}-1$ sehingga :

$$
h=e^{b}-1
$$

Dengan memangkatkan rumus (1) melalui bilangan $1 / t$ maka diperoleh rumus :

$$
h=\left[\frac{W_{t}}{W_{0}}\right]^{1 / t}-1
$$

Untuk menguji hipotesa yang diajukan digunakan Model Klasifikasi Dua Arah dengan Anak Contoh (Boer, 1989), melalui model :

$$
\begin{array}{cc}
Y_{i j k}= & \mu+\alpha_{i}+\beta_{j}+\tau_{i j}+\epsilon_{i j k} \\
\text { Ket }: i \quad & 0 \mathrm{~cm}, 30 \mathrm{~cm}, 60 \mathrm{~cm} \text { dari } \\
& \text { permukaan } \\
j \quad= & 20 \mathrm{~cm}, 25 \mathrm{~cm}, 30 \mathrm{~cm} . \\
k \quad= & 1,2,3 \\
Y_{i j k}= & \text { Nilai laju pertumbuhan } \\
& \text { Gracillaria sp. pada } \\
& \text { kedalaman ke-i, jarak tanam } \\
& \text { ke-j dan anak contoh ke-k } \\
= & \text { Pengaruh rataan umum. } \\
\mu \quad & \text { Pengaruh kedalaman ke-i }
\end{array}
$$

$\beta_{j} \quad=$ Pengaruh jarak tanam ke-j

$\tau_{i j} \quad=$ pengaruh kedalaman ke-i dan jarak tanam ke-j

$\epsilon_{i j k}=$ Pengaruh kedalaman ke-i, jarak tanam ke-j dan anak contoh ke-k

Untuk menentukan kedalaman dan jarak tanam yang memberikan pengaruh sama atau berbeda terhadap laju pertumbuhan relatif Gracillaria sp. digunakan Uji Duncan (Steel \& Torrie, 1993).

\section{HASIL DAN PEMBAHASAN}

Hasil pengukuran terhadap pertambahan bobot mutlak Gracilaria sp. di permukaan perairan dengan jarak tanam 20, $25,30 \mathrm{~cm}$ dan $60 \mathrm{~cm}$ meningkat dari bobot awal 50 gram menjadi 103,3 selama 6 minggu atau meningkat $49 \%$, sedangkan laju pertumbuhan relatif per minggu menurun dari 0,453 menjadi 0,127 pada setiap kedalaman dan pada jarak tanam yang berbeda. Hal ini menunjukkan Gracillaria sp yang ditanam dapat beradaptasi pada lingkungan dengan baik. Menurut (Anggadireja J.T., dkk, 2006) Rumput laut jenis ini mempunyai toleransi yang luas terhadap salinitas, dapat tumbuh pada kisaran salinitas 15 - 30 ppt. Dapat ditanam pada tambak yang masih dipengaruhi oleh pasang surut air laut, dasar tambak berupa pasir bercampur sedikit lumpur, suhu $20-28$ derajat, dan $\mathrm{pH} 6-9$ sehingga parameter kualitas air tersebut sesuai dengan kondisi tambak tempat penelitian dilakukan yaitu di Kecamatan Blanakan, Kabupaten Subang, Provinsi Jawa Barat. Dari hasil pengukuran diketahui bahwa pertumbuhannya terus meningkat sampai akhir penelitian. Sedangkan laju atau kecepatam tumbuhnya menurun seiring dengan umur Gracillaria sp semakin tua dan semakin rimbunnya tunas-tunas yang tumbuh sehingga menghambat laju pertumbuhan. Oleh karena itu Rumput laut 
dapat dipanen pada umur 1,5 - 2,0 bulan setelah ditanam. Apabila panen kurang dari umur tersebut maka akan dihasilkan rumput laut berkualitas yang rendah (Zatnika, A 2000). Hal ini dikarenakan kandungan agar keraginan yang dikandungnya menjadi rendah dan kekuatan gel (gelstrength) dari agar juga rendah, tetapi kadar airnya tinggi. Kondisi seperti ini tidak dikehendaki oleh industri pengolah rumput laut sehingga akan dihargai lebih rendah.

Laju pertumbuhan Gracillaria sp. yang diukur adalah laju pertumbuhan bobot pada saat minggu ke-t terhadap bobot awal. Hasil pengukuran laju pertumbuhan Gracillaria sp. Setiap minggu atau perubahan selama 6 minggu berdasarkan kedalaman dan jarak tanam berbeda disajikan dalam Gambar 1 .

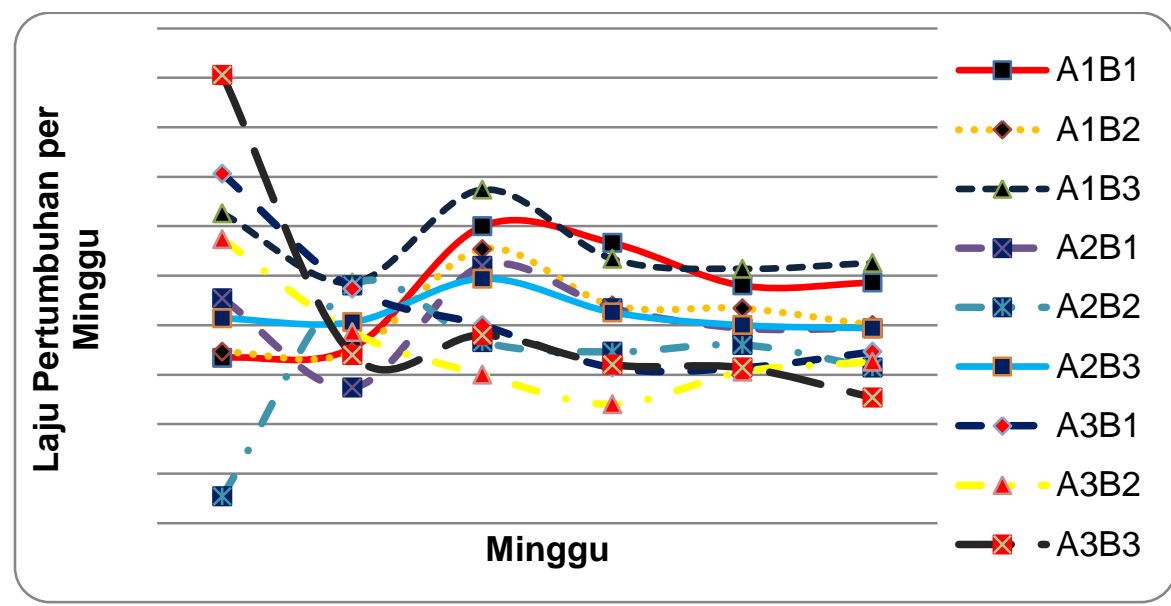

Gambar 1. Laju Pertumbuhan Garcillaria sp. selama 6 minggu untuk semua kedalaman dan jarak tanam.

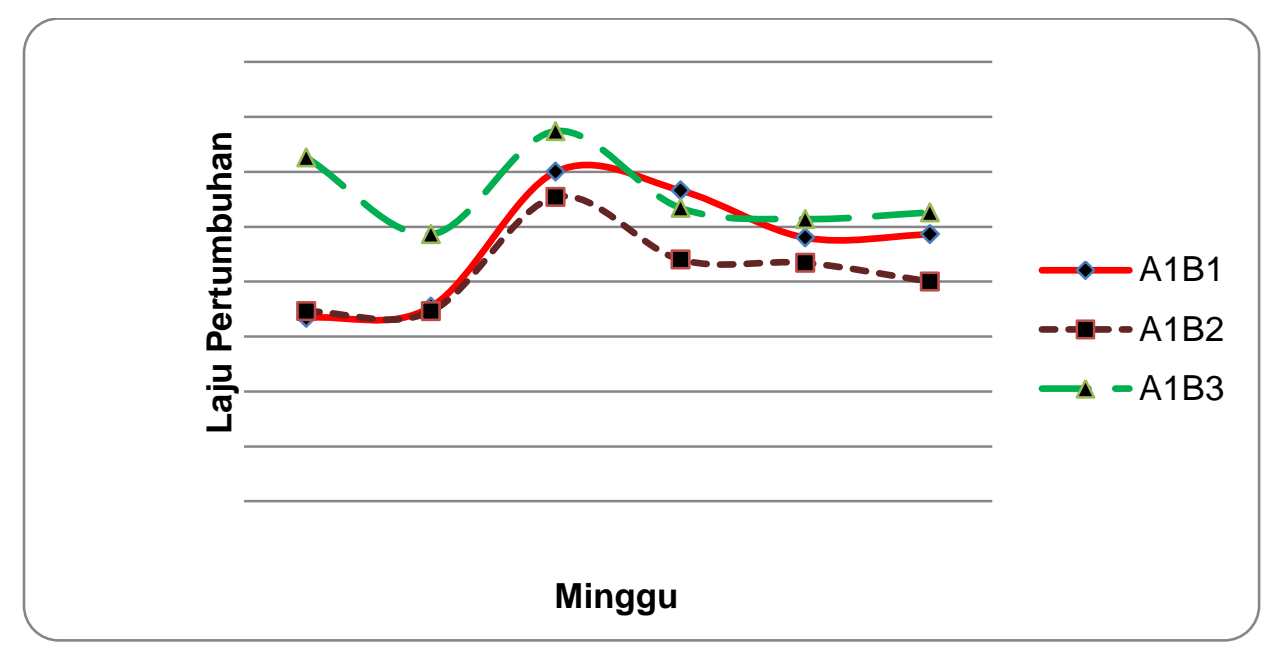

Gambar 2. Laju pertumbuhan Gracilaria sp. selama 6 minggu pada kedalaman di permukaan untuk jarak tanam $20 \mathrm{~cm}$ (A1B1), $25 \mathrm{~cm}$ (A1B2), dan $30 \mathrm{~cm}$ (A1B3). 


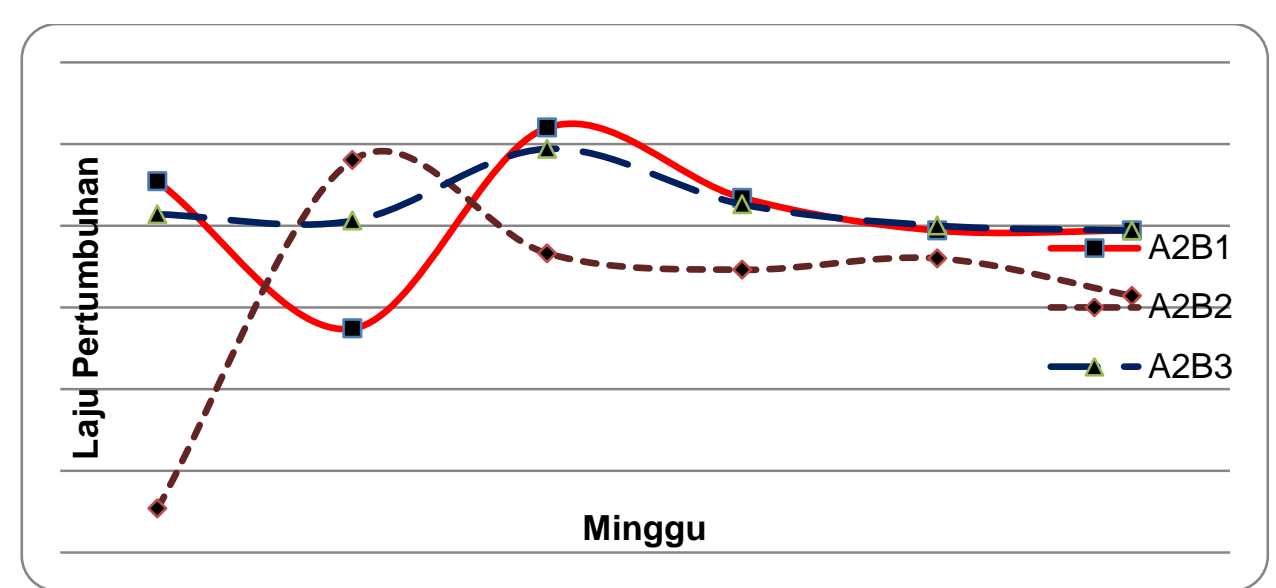

\section{Gambar 3. Laju pertumbuhan Gracillaria sp. selama 6 minggu pada kedalaman $30 \mathrm{~cm}$ dari permukaan dan jarak tanam $20 \mathrm{~cm}$ (A1B1), $25 \mathrm{~cm}$ (A1B2), dan $30 \mathrm{~cm}$ (A1B3).}

Pada Gambar 2, 3, dan 4 terlihat bahwa Gracillaria sp. yang ditanam di permukaan dengan jarak tanam yang sama mempunyai rata-rata laju pertumbuhan lebih tinggi dari yang ditanam di kedalaman 30 dan $60 \mathrm{~cm}$ dari permukaan perairan. Begitu juga halnya dengan rata-rata laju pertumbuhan rumput laut Gracillaria sp. yang ditanam pada kedalaman $30 \mathrm{~cm}$, lebih baik dari kedalaman $60 \mathrm{~cm}$ untuk jarak tanam yang sama. Menurut Kadi dan Atmadja (1988) bahwa salah satu faktor penting yang menyebabkan perbedaan laju pertumbuhan tersebut adalah perbedaan intensitas cahaya yang diterima oleh algae pada kedalaman yang berlainan. Hal yang sama dikemukan juga oleh Nybaken, 1992. Kondisi lingkungan perairan di tambak tempat penelitian dilakukan cukup baik dan cerah sehingga cahaya matahari dapat menembus ke dalam dasar air. Suhu air sekitar $28{ }^{\circ} \mathrm{C}$, salinitas 15 per mil dan $\mathrm{pH}$ air 7 serta dasar perairan berupa pasir dan sedikit berlumpur, sehingga cukup mendukung pertumbuhan rumput laut. Lokasi tambak yang masih dipengaruhi oleh pasang surut air laut sehingga memudahkan pergantian air di dalam tambak. Selain itu faktor lain yang sangat berpengaruh pada pertumbuhan adalah penyediaan dan pemilihan bibit yang baik dan sehat.

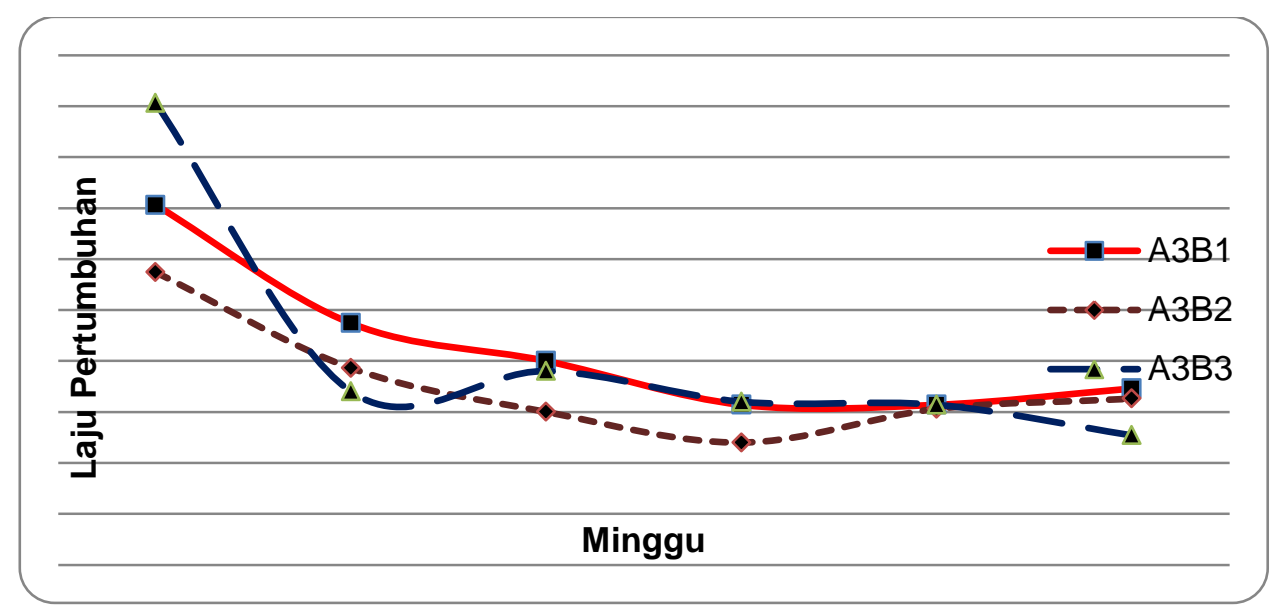

Gambar 4. Laju pertumbuhan Gracillaria sp. selama 6 minggu pada kedalaman $60 \mathrm{~cm}$ dari permukaan untuk jarak tanam $20 \mathrm{~cm}$ (A1B1), 25cm (A1B2), dan $30 \mathrm{~cm}$ (A1B3). 
Dari Gambar 2, 3, dan 4 di atas, juga terlihat bahwa rata-rata laju pertumbuhan rumput laut Gracilaria sp. yang dibedakan atas jarak tanam $(20,25$, dan $30 \mathrm{~cm})$ pada kedalaman dipermukaan menunjukkan bahwa jarak tanam $30 \mathrm{~cm}$ mempunyai laju pertumbuhan tertinggi, kemudian diikuti oleh jarak tanam 20 dan $25 \mathrm{~cm}$. Pada kedalaman 30 dan $60 \mathrm{~cm}$, rata-rata laju pertumbuhan tertinggi terjadi untuk jarak tanam $20 \mathrm{~cm}$ dan kemudian diikuti oleh jarak tanam 30 dan 25 $\mathrm{cm}$.

Bedasarkan analisis sidik ragam diketahui bahwa selama pengamatan 6 minggu kecuali minggu I dan II, perbedaan kedalaman memberikan pengaruh nyata terhadap laju pertumbuhan rumput laut Gracilaria sp. pada selang kepercayaan $95 \%$, dan jarak tanam dalam penelitian ini tidak memberikan pengaruh nyata terhadap laju pertumbuhan Gracilaria sp. pada selang kepercayaan yang sama. Perbedaan jarak tanam tidak memberikan pengaruh nyata terhadap laju pertumbuhan rumput laut Gracilaria sp. Hal ini diduga karena perbedaan jarak tanam pada masing-masing taraf (perlakuan) terlalu kecil.

Tabel Analisis Sidik Ragam laju pertumbuhan Gacilaria sp. selama 6 minggu.

\begin{tabular}{ccc}
\hline \multirow{2}{*}{ Minggu } & \multicolumn{2}{c}{ Sumber Keragaman } \\
& Kedalaman $(A)$ & Jarak Tanam (B) \\
\hline I & $*$ & - \\
III & - & - \\
IV & $* *$ & - \\
V & $* *$ & - \\
VI & $* *$ & $*$ \\
\hline
\end{tabular}

Keterangan :

$$
\begin{array}{ll}
* * \quad & =\text { nyata pada } \alpha=0,01 \\
* \quad & =\text { nyata pada } \alpha=0,05 \\
-\quad & =\text { tidak nyata pada } \alpha=0,05 \text { dan } \alpha=0,01
\end{array}
$$

Berdasarkan uji Duncan terlihat bahwa antar kedalaman (di permukaan, 30 dan 60 $\mathrm{cm}$ dari permukaan) memberikan pengaruh nyata terhadap laju pertumbuhan Gracilaria sp. Perbedaan tersebut terlihat nyata pada Gambar 1.

\section{KESIMPULAN DAN SARAN}

\section{Kesimpulan}

Berdasarkan hasil pengamatan dan observasi di lapangan, beberapa hal yang dapat disimpulkan adalah :
1) Pertambahan bobot mutlak Gracilaria sp. di permukaan perairan dengan jarak tanam $20 \mathrm{~cm}, 25 \mathrm{~cm}, 30 \mathrm{~cm}$ dan $60 \mathrm{~cm}$ meningkat dari bobot awal 50 gram menjadi 103,3 selama 6 minggu atau meningkat $49 \%$, sedangkan laju pertumbuhan relatif per minggu menurun dari 0,453 menjadi 0,127 pada setiap kedalaman dan pada jarak tanam yang berbeda.

2) Laju pertumbuhan rumput Gracillaria sp yang ditanam pada permukaan air lebih baik dibandingkan laju pertumbuhan pada kedalaman 30 
dan $60 \mathrm{~cm}$ pada jarak tanam 20, 25 dan $30 \mathrm{~cm}$.

3) Laju pertumbuhan rumput Gracillaria sp yang ditanam pada kedalaman 30 $\mathrm{cm}$ dari permukaan lebih baik dibandingkan laju pertumbuhan pada kedalaman $60 \mathrm{~cm}$ pada jarak tanam yang sama.

4) Hasil analisis sidik ragam maupun uji Duncan memperlihatkan bahwa perbedaan kedalaman penanaman rumput Gracillaria sp berpengaruh nyata, sedangkan perbedaan antar jarak tanam tidak berpengaruh nyata terhadap laju pertumbuhan.

\section{Saran}

Rumput Gracillaria sp dapat dipanen pada waktu umur kurang dari 60 hari dan penanamannya dilakukan pada kedalaman 20, 25 atau $30 \mathrm{~cm}$ dari permukaan perairan.

\section{DAFTAR PUSTAKA}

Atmaja, W.S., 1979. Mengenal jenis-jenis Rumput Laut Budidaya, Pewarta Oceana, Vol 5. Jakarta

Aggadiredja, Jana T., dkk, 2006. Rumput laut. Seri Agribisnis. Pembudidayaan, Pengolahan dan Pemasaran komoditas Perikanan Potensial. Penebar Swadaya. Jakarta.

Zatnika, A., 2000. Perkembangan Industri Rumput Laut Indonesia, Forum Rumput Laut Nasional. Jakarta

Kementrian Kelautan dan Perikanan (KKP), 2010. Kelayakan Usaha Budidaya Rumput Laut. Seri Paket Analisa Usaha Budidaya Perikanan. Direktorat Pemberdayaan Masyarakat Pesisir. Jakarta.

Nybaken, J.W. 1992. Biologi Laut: Suatu Pendekatan Ekologis. Gramedia . Jakarta.
Ricker, W.E., 1975. Computation and Interpretation of Biological Staistics of Fish Populations. Bull. Fish. Res. Can.

Soegiarto, dkk, 1978. Rumput Laut (Algae): manfaat, potensi, dan Usaha Budidayanya, LON-LIPI. Jakarta.

Steel RGD and Torrie JH, 1993. Prinsip dan prosedur statistik. Suatu Pendekatan biometrik. Terjemahan. Edisi Kedua. Gramedia Pustaka Utama. Jakarta. 